Bajopas Volume 3 Number 2 December, 2010

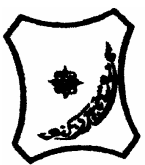

Bayero Journal of Pure and Applied Sciences, 3(2): 4 - 8

Received: May, 2010

Accepted: September, 2010

ISSN 2006 - 6996

\title{
ACUTE NICOTINE INDUCED PRESSOR RESPONSE IS IN PART DUE TO INTERACTION WITH BARO REFLEX PATHWAY
}

\author{
*Dikko, A. U. and Dikko, H. A. \\ Department of Physiology, Faculty of Medicine, Bayero University, Kano \\ *Correspondence author
}

\begin{abstract}
Arterial baro-reception is regarded as one of the most powerful rapidly acting homeostatic mechanism regulating blood pressure. Investigation had suggested that nicotine may interact with aortic baro-receptors to produce its sustained presser response, an effect that had received little attention. Anaesthetized Wister albino rats were used. Bilateral carotid occlusion (BCO) method was used to introduce a predominantly sympathetically mediated cardiovascular reflex. Baroreceptor sensitivity (BS) test was assessed as gain in baroreflex function. Others BCO led to

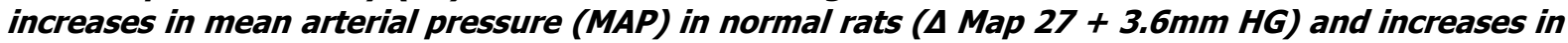
$M A P$ induced by BCO was less after nicotine pretreatment $(P<0.001)$. BCO also led to significant increases in heart rate in both normal and in nicotine treated rats but the increases shows no significant differences. Acute nicotine pretreatment reduced BS evoked by presser stimulus (phenylephrine) from 0.789, 0.039 and 0.004 beats per min $\mathrm{mm} \mathrm{HG-1} \mathrm{(P<0.001).} \mathrm{The} \mathrm{significant}$ decreases in $B C O$ reduced presser response by nicotine may be an indication of strong pre-existing sympathetic activation. Reduction of BS by nicotine may be an indication that nicotine do interact with beroreflex pathway either peripherally at the receptors or centrally to reset the system. Thus nicotine action on baro-reflex system could contribute to the sustained presser response it produced.
\end{abstract}

Key words: Baroreceptors, Means Arterial Pressure (MAP), Baroreflex, Baro - reception

\section{INTRODUCTION}

Although, nicotine was found to decrease the risk of pre-eclampsia in pregnant women by reduction of production of cytokines by the placenta (Oonagh Dowling et al., 2010). Acute nicotine administration whether by smoking or intravenous injection is generally accepted to increase blood pressure and heart rate in most animals and in human subjects (Squire et al., 1984; Aceto et al., 1981; Benowich et al., 1986; Gropelli et al., 1990). The effects are also associated with pregnant women, thus; smoking during pregnancy was found to cause adverse effects including: spontaneous abortion (George et al., 2006), placenta previa (Chelmow et al., 1996), placental abruption (Ananth et al., 1999), preterm birth (Fantuzzi et al., 2007), stillbirth (Hogberg and Cnattingius, 2007), fetal growth restriction (Hammoud et al., 2005; Nordentoft et al., 1996), low birthweight (Jaddoe et al., 2008), and sudden infant death syndrome (SIDS) (Mitchell and Milerad, 2006). Stoppage of was found to reduce the damage to the developing fetus (Pickett et al., 2003). Smoking cessation therapy was found to reduce the incidence of low birth weight and preterm birth (Lumley et al., 2004).

Cigarette smoking in animal models exposed to nicotine during gestation and lactation leads to defective; metabolic (Bruin et al., 2008), reproductive (Anzar et al., 2006; Lagunov et al., 2009), cardiovascular (Gao et al., 2005, 2008), pulmonary (Petre et al., 2008) outcomes in the offspring.
These effects of cardiovascular associated symptoms are primarily mediated through the activation of sympathetic nervous system (Cryer et al., 1976; Mancia, 1990; Winnifford et al., 1990), leading to increases in sympathetic tone with resultant increases in blood pressure, heart rate and coronary vasoconstriction similar to various cardiovascular reflex like cold presser test, isometric and dynamic exercise Mudge et al., 1976; Brown et al., 1984; Berkenboom et al., 1986). The extent of the haemodynamic changes that induced those cardiovascular reflexes depend mainly on the integrity of the baroreceptor reflex system. Arterial baroreflex system is regarded as one of the most powerfully rapidly acting homeostatic mechanism for regulating blood pressure (Abdul-Rahman et al., 1987).

Mendel et al. (1973) had shown that, nicotine, in conscious dogs induces bradycardia after the initial tachycardia and suggested that it is probably due to baroreceptor stimulation. It had also been reported that since the heart rate increases due to nicotine become normal in the presence of persistent increases in blood pressure, this may suggest some baroreceptor accommodation (Mendel et al., 1973). Robert et al. (1988) suggested that nicotine may interact with aortic baroreceptor system in producing its sustained presser response, an effect which had received very little attention. Hence the effect of acute nicotine on baroreflex sensitivity and on bilateral carotid occlusion test was investigated. 


\section{MATERIALS AND METHODS}

The experiments were performed on Wister albino rats, weighing from $150-200 \mathrm{~g}$ (Animal Centre, College of Medicine Lagos). The animals were anaesthetized with a mixture of alpha chloralose ( $1 \% \mathrm{~W} / \mathrm{V})$ and urethane $(25 \% \mathrm{~W} / \mathrm{V})$ at a dose level of $5 \mathrm{ml} / \mathrm{kg}$, injected intraperitioneally. Femoral artery and vein were isolated and cannulated with Luer polyethylene cannula filled with $150 \mathrm{mmol} / \mathrm{kg} \mathrm{NaCI}$ solution. Heparin (Upjhon U.S.A.) 100 I.U/l00g I/V was injected. The arterial cannula was used for recording arterial blood pressure and heart rate, while the venous cannula was used for injecting drugs and saline. The carotid arteries were isolated for bilateral carotid occlusion tests. Body temperature was maintained at $36-38{ }^{\circ} \mathrm{C}$ using overhead tamp when necessary. The rats were fasted 24 hours prior any experimentation. The drugs used were Nicotine (Waco pure chem. Japan) and phenylephrine (Sigma chem. Co) all dissolved in 150 $\mathrm{mmol} / \mathrm{L}$ saline.

\section{MEASUREMENT AND SPECIAL PROCEDURES}

The arterial blood pressure was continuously recorded from cannulated artery, with a pressure transducer (P23 D Hato Rey Inc) placed at heart level. Heart rate was obtained from blood pressure recording and confirmed with a tachometer. The measurements were recorded on Grass polygraph model 7D (Grass Instrument Ltd. Quincy Mass U.S.A.).

Baroreceptor sensitivity was assessed as the gain in baroreflex function using methods previously described by others (Korner et al., 1972 and Rothbaum et al., 1974). Graded increase in arterial blood pressure was induced by injecting serial bolus doses of Phenylephrine. The peak changes in MAP $(\triangle M A P)$ together with reflex changes in heart rate $(\Delta$ $\mathrm{HR}$ ) were used to calculate baroreceptor reflex sensitivity (BS). This was done by plotting a curve of changes in heart rate (Y-axis) against MAP changes (X-axis). The BS was expressed in beats $\mathrm{min} / \mathrm{mmHg}-1$, was obtained from the slope of the curve (Goldstein, 1983).

Bilateral carotid occlusion (BCO) method was used to introduce a predominantly sympathetic mediated cardiovascular reflex (Ledsome and Linden 1964; Adigun et al., 1984 and 1991). The occlusion clips were applied below the carotid sinus for 30 seconds.

\section{Experimental Protocol}

1. The effect of graded intravenous infection of nicotine $(50-800 \mu \mathrm{m} / \mathrm{kg})$ on blood pressure and heart rate was done. Maximal changes was seen at $500 \mathrm{ug} / \mathrm{kg}$ dosage, thus the dose level used for subsequent experiments.

2. BCO: Normal rats were exposed to $\mathrm{BCO} 3$ time at 20 minutes intervals, after which they were given nicotine $(500 \mu \mathrm{g} / \mathrm{kg} \mathrm{I} / \mathrm{V})$ then followed by 3 exposure to BCO at 20 minutes interval. Each exposure lasted 30 seconds. $(n=8)$.

3. BS: Barorefiex sensitivity was tested using a vasopressor stimulus (phenylephrine 0.5 $-5 \mu \mathrm{g} / \mathrm{kg}$ ) as previously described above. The test was carried out in normal rats and in nicotine treated rats $(500 \mu \mathrm{g} / \mathrm{kg}) .(\mathrm{n}=8)$.

\section{Statistical Analysis}

Mean arterial pressure (MAP) was calculated as MAP = diastolic pressure $+1 / 3$ pulse pressure $\mathrm{mmHg}$. The results are presented as mean SEM. Paired and unpaired student $T$ test was used to assess statistical significance $(P<0.001)$.

\section{RESULTS}

Intravenous injection or nicotine, $500-800 \mu \mathrm{g} / \mathrm{kg}$ led to transient bradycardia and hypotension followed by sustained pressor and tachycardiac response $(P<0.001)$. Maximal changes in pressor and tachycardia response was seen at $500 \mu \mathrm{g} / \mathrm{kg}$ dose level ( $\triangle$ MAX MAP $52.5 \pm 1.2 \mathrm{mmHg}$, $(\triangle$ MAX HR $71.67 \pm 12.2$ beats $/ \mathrm{min})$.

BCO led to increases in MAP in both normal rats ( $\triangle$ MAX $27.8 \pm 2.1 \mathrm{mmHg}, \mathrm{P}<0.001$ ) and in nicotine treated rats $(\triangle \mathrm{MAX} 14.6 \pm 1.8 \mathrm{mmHg}$, $p<0.001$. The increases in MAP was smaller after nicotine treatment $(p<0.00 \mathrm{l})$. BCO also led to significant increases in heart rate in both normal and in nicotine treated rats, but the increases shows no significant differences (Table 1). Acute nicotine administration also reduced baroreflex sensitivity evoke with a pressure stimulus from $0.789+0.039$ to $0.332+0.04$ beats min- $1 \mathrm{mmHg}-1(\mathrm{p}<0.001)$, (Table 2).

Table 1: Maximal Changes MAP and HR Induced by Bilateral Carotid Occlusion before and after Nicotine Treatment (MEAN \pm SEM) $n=s$.

\begin{tabular}{ccc}
\hline & $\boldsymbol{\Delta}$ MAP $\mathbf{~ m m h g}$ & $\boldsymbol{\Delta}$ HR beats $\mathbf{~ m i n}^{\mathbf{- 1}}$ \\
\hline Before Nicotine & $27.8 \pm 2.1$ & $26.6 \pm 23$ \\
After Nicotine & $14.6 \pm 1.8^{\mathrm{s}}$ & $303 \pm 3.2^{\mathrm{s}}$ \\
\hline
\end{tabular}

Table 2: Baroreflex Sensitivity (BS) in Normal Rats and in Nicotine Treated Rats (MEAN + SEM). BS = Heart rate beats $\mathrm{min-1} \mathbf{~ m m H g}^{-1}$ Mean (MAP)

Normal rats

$0.789 \pm 0.039$ Nicotine treated rats $0.322 \pm 0.04^{\mathrm{S}}$

Key: Not Significant $=$ NS, Significant $=S(P<0.001)$. 


\section{DISCUSSION}

Cigarette smoking an as endemic hobby that traverses across the world population is associated with various diseases ranging from cardiovascular and respiratory, to the ones affecting pregnant mothers and their children in stillbirth (Hogberg and Cnattingius, 2007), fetal growth restriction (Hammoud et al., 2005; Nordentoft et al., 1996), low birthweight (Jaddoe et al., 2008), and sudden infant death syndrome (SIDS) (Mitchell and Milerad, 2006). This resulted in governments intervention in the field of laws curtailing smoking and research.

Some researchers found that BCO to produce a predominantly sympathetic mediated reflex. A reduction of BCO-induced pressure response, will hence implied a decrease in sympathetic activation (Adigun et al., 1984 and 1991). Thus, it was found that the paradoxical decreases in pressure response due to BCO by nicotine pretreatment may be due a strong preexisting sympathetic activation since both nicotine and BCO-induced presser responses is predominantly mediated by activation of the system. The dose level of nicotine used in treating the rats prior to $\mathrm{BCO}$ is the level that produces maximal presser response, thus indicating maximal nicotinic activation of the sympathetic system. This is in agreement with prior report showing of nicotineinduced homodynamic changes and some cardiovascular tests that increases sympathetic changes and some cardiovascular tests that increases sympathetic tone, occur at low nicotine dosage level only (Perkin et al., 1990).

A decline in baroreflex function is due to two major possibilities. First, pathological arterial changes

\section{REFERENCES}

Abdul-Rahman, ARA. Merril RH. and Wooles WW. (1987): Effect of acute ethanol administration on baroreceptor reflex control of heart rate in human volunteer: CLIN SCI 72: 113-22.

Aceto SA. Martine B.R., Uwaid A.H., Immay. E.L. (1981): Optically pure (+) nicotine and biological camparism with (-) nicotine: J MED CHEM: 174-77.

Adigun S.A., Fentem P.H (1984): Comparism of the effects of salbutomol, etilefrine and dextran during hypotension and low cardiac output state in rabbits: CLIN EXP PHARMACOL PHYSIOL 11:627.43.

Adigun S.A., Akinjuola O.B. (1991): Salt-induced hypertension is maintained by automatic nervous system, calcium but not rennin angiotensin system. vasopressin and prostaglandins: NIG J PHYSIOL SCI 7(1): 110.

Ananth, C. V., Smulian, J. C., and Vintzileos, A. M. (1999). Incidence of placental abruption in relation to cigarette smoking and hypertensive disorders during pregnancy: a that reduce the distensibility of the vessel wall with miss match increases in compensatory receptor sensitivity (Sapru and Wang, 1976; Anderson et al., 1980; Anderson and Brown, 1980). Secondly, the functional derangement in autonomic nervous tone (Volpe et al., 1982). The acute nature of this experiment makes the reduction of baroreflex sensitivity entirely accountable for by increased sympathetic activity (beta adrenergic increase in heart rate) and or reduced parasympathetic tone (Pickering et al., 1972; Julius and Elser, 1975; Takeshita et al., 1978; Wallace, 1975; Johnson, 1980; Goldstein, 1983; Adigun et al., 1984 and 1991).

The reduction of BS by nicotine is in concurrence with it's known activation of sympathetic nervous system (Cryer et al., 1976; Mancia, 1990 and Winnifford et al., 1990). It is also an indication that nicotine do interact with baroreflex pathway to inhibit baroreflex response either 1 . Centrally: to increase sympathetic activity, similar to stimulation of hypothalamic or rage centre in laboratory animals (Hilton, 1965) and events occurring in man stress (Brod et al., 1959), exercise (Pickering et al., 1972) and heart failure (Julius et al., 1971) and or 2. peripherally, by interacting with the receptors to reduces afferent information to the centre, as has been observed in afferent traffic oblation experiment in animals (Doba and Reis, 1973; Nathan and Reis, 1977). Thus acute nicotine-induced in baroreflex sensitivity, indicating reduced baroreflex buffering of arterial blood pressure might lend an important contribution to the sustained blood pressure response it produces.

meta-analysis of observational studies. Obstet. Gynecol. 93, 622-628.

Anderson M.C., Kuraka S. Brown A.M. (1980): Baroreceptor function and changes in strain sensitivity in normotensive and spontaneous hypertensive rats: CIR RES 47: 821-8.

Anderson M.C., Brown A.M. (1980): Baroreceptor function in spontaneous4y hypertensive rats: Cir RES 47: 828-34.

Anzar, M., Buhr, M., Mirshokraei, P., and Holloway, A. C. (2006). Fetal and Neonatal Exposure to Nicotine Adversely Affects Testicular and Epididymal Function in Rats. Society for the Study of Reproduction, Omaha, NE.

Benowitch N.L. (1986): Clinical pharmacology of nicotine. ANNU REV MED 37:21-32.

Berkenboom G.M. Abromowitz M. Vandermotes P. Degre S.G. (1986): Role of alpha adrenergic coronary tone in exercise induced angina pectoris: AM J CARDIOL 57: 197-99.

Brad J. Fenc V. Heijl Z. Jirka J. (1959): Circulatory changes underlying blood pressure elevation during emotional stress in normotensive and hypertensive subjects: CLIN SCI 18: 269-79. 
Bruin, J. E., Petre, M. A., Lehman, M. A., Raha, S. Gerstein, H. C., Morrison, K. M., and Holloway, A. C. (2008). Maternal nicotine exposure increases oxidative stress in the offspring. Free Radic. Biol. Med. 44, 19191925.

Brown B.G., Lee A.B., Bolson, E.I. Oddee H.T. (1984): Reflex constriction of coronary stenosis as a mechanism contributing to ischemic left ventricular dysfunction during isometric exercise: CIR 70: 18-24.

Chelmow, D., Andrew, D. E., and Baker, E. R. (1996). Maternal cigarette smoking and placenta previa. Obstet. Gynecol. 87, 703-706.

Cryer P.E., Haymond M.W., Santiago J.V., Sha S.D. (1976): Norepinephrine and epinephrine release and adrenergic mediation of smoking associated with haemodynamic events (1976): N ENGL J MED 295: 573-7.

Deta N. and Reis D.J. (1973): Acute fulmugating neurogenic hypertension produced by brain stern lesion in rats: CIR RES 32: 584-90.

Fantuzzi, G., Aggazzotti, G., Righi, E., Facchinetti, F., Bertucci, E., Kanitz, S., Barbone, F., Sansebastiano, G., Battaglia, M. A., Leoni, V., et al. (2007). Preterm delivery and exposure to active and passive smoking during pregnancy: a case-control study from Italy. Paediatr. Perinat. Epidemiol. 21, 194-200.

Gao, Y. J., Holloway, A. C., Su, L. Y., Takemori, K., Lu, C., and Lee, R. M. (2008). Effects of fetal and neonatal exposure to nicotine on blood pressure and perivascular adipose tissue function in adult life. Eur. J. Pharmacol. 590, 264-268.

Gao, Y. J., Holloway, A. C., Zeng, Z. H., Lim, G. E., Petrik, J. J., Foster, W. G., and Lee, R. M. (2005). Prenatal exposure to nicotine causes postnatal obesity and altered perivascular adipose tissue function. Obes. Res.13, 687692.

George, L., Granath, F., Johansson, A. L., Anneren, G., and Cnattingius, S. (2006). Environmental tobacco smoke and risk of spontaneous abortion. Epidemiology 17, 500-505.

Goldstein D.S. (1983) Arterial baroreflex sensitivity, plasma catecholamines and presser responsiveness in essential hypertension: CIR 68: 234-40.

Gordon FJ., and Mark AL. (1983): impaired baroreflex control in pre-hypertensive Dahl rats: AM J PHYSIOL 245:H210-7.

Groppelli A. Omboni S. Parati G. Mancia G. (1990): Blood pressure and heart rate responses to repeated smoking before and after beta blockade and selective alpha-1 adrenoceptor inhibition: J HYPERTENS 8(s5): s35-40.
Hammoud, A. O., Bujold, E., Sorokin, Y., Schild, C., Krapp, M., and Baumann, P. (2005). Smoking in pregnancy revisited: Findings from a large population-based study. Am. J. Obstet. Gynecol. 192, 1856- 1862; discussion 18621863.

Hilton S.M. (1965): Hypothalamus control of cardiovascular responses in fear and rage. In: Scientific basis of medicine: ANN REV pp 217-38.

Hogberg, L., and Cnattingius, S. (2007). The influence of maternal smoking habits on the risk of subsequent stillbirth: is there a causal relation? BJOG 114, 699-704.

Jaddoe, V. W., Troe, E. J., Hofman, A., Mackenbach, J. P., Moll, H. A., Steegers, E. A., and Witteman, J. C. (2008). Active and passive maternal smoking during pregnancy and the risks of low birthweight and preterm birth: the Generation R Study. Paediatr. Perinat. Epidemiol. 22, 162-171.

Johnson LC. (1980): Abnormal heart rate response to a deep breath in baroreflex hypertension; a sign of autonomic nervous dysfunction: AM HEART J 99: 487-93.

Julius S. Pascual, AV. and London R. (1971): Role of parasympathetic inhibition in the hyperkinetic type of borderline hypertension: CIR 44:4138.

Julius S. and Elser M. (1975): Automatic nervous cardiovascular regulation in borderline hypertension: AM J CARDIOL 36: 685-96.

Komer PJ. Shaw J. West M.J. and Oliver J.R. (1972): Central nervous control at baroreceptor reflexes in rabbits: CIR RES 31: 639-52.

Lethome JR. and Linden R.J. (1964): Effects of bretylium tosytate on some cardiovascular reflexes: J Physiol 170: 442-55.

Lagunov, A., Sadeu, J. C., Bruin, J. E., Woynillowicz, A. K., Foster, W. G., and Holloway, A. C. (2009). Effect of fetal and lactational exposure to nicotine on spermatogenesis in Wistar rats. Canadian Fertility and Andrology Society 55th Annual Meeting, Montreal, QC.

Lumley, J., Chamberlain, C., Dowswell, T., Oliver, S., Oakley, L., and Watson, L. (2009). Interventions for promoting smoking cessation during pregnancy. Cochrane Database Syst. Rev. CD001055. 372 BRUIN, GERSTEIN, AND HOLLOWAY.

Mancia G. (1990): Cardiovascular effects of smoking: CLIN EXP HYPERTENS A 12(5): 917-29.

Mendel W.J., Laks M. and Hayakawa J.(1973): Cardiovascular effects of nicotine in conscious dogs: AM J CARDIOL 32: 347-55. 
Mitchell, E. A., and Milerad, J. (2006). Smoking and the sudden infant death syndrome. Rev. Environ. Health 21, 81-103.

Mudge G.H., Grossman W. and Wills R.M. jr.(1976): Reflex increase in coronary vascular resistance in patients with ischemic heart diseases: N ENGL J MED 295: 133-7.

Nathan A.N. and Reis D.J. (1977): Chronic liable hypertension produce by lesion at nucleus tracts solitarius in cats: CIR RES 40:72-80.

Nordentoft, M., Lou, H. C., Hansen, D., Nim, J., Pryds, O., Rubin, P., and Hemmingsen, R. (1996). Intrauterine growth retardation and premature delivery: the influence of maternal smoking and psychosocial factors. Am. J. Public Health 86, 347-354.

Pickett, K. E.,Wakschlag, L. S., Dai, L., and Leventhal, B. L. (2003). Fluctuations of maternal smoking during pregnancy. Obstet. Gynecol. 101, 140-147.

Petre, M. A., Labiris, R. N., Inman, M. D., and Holloway, A. C. (2008). Fetal and neonatal exposure to nicotine disrupts postnatal lung development. Annual Meeting of the American Thoracic Society, Toronto, ON, May.

Perlun K. A. Epstein L. H. and Atiler R. L. (1 990): Cardiovascular effect of nicotine during physical activity arid meal consumption: CLIN EXP PHARMACOL HYSIOL 17(S): 327-34.

Robertson D. Tseng C. and Appalsamy N. (1988): Smoking and cardiovascular control: AM HEART J 155:258-62.

Rothbaurn D. A. and Shaw D. S. (1974): Age difference and baroreceptor response of rats: AM J GERONT 29: 458-62.

Sarpu H. N. and Wang S. C. (1976): Modification of baroreceptor sensitivity in spontaneous hypertensive rats: AM J PHYSIOL 230: 66471.

Squires W.G., Brandon T.A. and Ziwkgraf S. (1984): Haemodynamic effects of oral smokeless tobacco in dogs and young adults: PREV MED 13: $195-206$.

Takeshita A. Tanaka S. Kuroiwa A. and Nacamura N. (1978): Reduced baro receptor sensitivity in borderline hypertension: CIR 51: 738-42.

Volpe M. Trimator B. and Ricciadelli B.(1982): The autonomic nervous tone abnormalities in the genesis of the impaired baroreflex responsiveness in borderline hpertensive subjects: CLIN SCI 62: 581-88.

Winnilord M. D. (1990): Smoking and cardiovascular function: J HYPERTENS 8(suppl. 5): 517-23. 